\title{
EFEKTIVITAS E-LEARNING BERBASIS MOODLE DI SMK KARYA GUNA KELAS XI TKJ II MATERI AJAR PRAKTIK JARINGAN KOMPUTER
}

\author{
${ }^{1}$ Desi Andriani Sitanggang, ${ }^{2}$ Bambang P. Adhi, ${ }^{3}$ Diat Nurhidayat \\ ${ }^{1}$ Mahasiswa, ${ }^{2}$ Dosen Pembimbing I, ${ }^{3}$ Dosen Pembimbing II \\ Program Studi S1 Pendidikan Teknik Informatika dan Komputer \\ Universitas Negeri Jakarta \\ Email: andrianidesi71@gmail.com, bambangpadhi@unj.ac.id, diat@unj.ac.id
}

\begin{abstract}
Abstrak
Penelitian ini dilakukan dengan tujuan untuk melihat sejauh mana peserta didik dan guru dalam menerima elearning yang berbasis moodle pada SMK Karya Guna dalam proses pembelajaran kedepannya. Penelitian ini menggunakan pendekatan penelitian dan pengembangan (Research and Development) yang bertempat di SMK Karya Guna. Penelitian dilakukan sejak Agustus 2017 hingga Juli 2018. Penelitian ini dilakukan terhadap siswa kelas XI TKJ II yang telah mengikuti pelajaran Praktik Jaringan Komputer dan guru TKJ SMK Karya Guna. Tahapan dari penelitian ini adalah potensi dan masalah yang ada, rancangan produk, pembuatan produk, uji coba produk, revisi produk dan implementasi. Penelitian ini diujikan kepada dosen ahli media, dosen ahli elearning, guru dan siswa. Hasil pengujian dari ahli media untuk versi 3 mendapatkan nilai presentase 88\%, oleh ahli e-learning sebesar 85,71, oleh siswa dan guru (kelompok besar) sebesar 92,26\% dan 90\%. Berdasarkan hasil uji tersebut, dapat disimpulkan bahwa e-learning berbasis moodle versi ketiga sesuai dan dapat diterima dengan baik untuk diterapkan pada mata pelajaran Praktik Jaringan Komputer.
\end{abstract}

Kata Kunci: e-learning, MOODLE, TAM

\section{PENDAHULUAN}

Perkembangan teknologi informasi dan komunikasi telah membawa perubahan yang sangat besar bagi kemajuan dunia pendidikan. Seiring dengan perkembangan tersebut metode pembelajaran juga banyak mengalami perkembangan, baik metode pembelajaran secara personal ataupun proses pembelajaran. Bentuk dari perkembangan teknologi informasi yang diterapkan di dunia pendidikan adalah e-learning.

E-learning adalah instruksi yang disampaikan pada perangkat digital seperti komputer yang ditujukan untuk mendukung pembelajaran. Elearning dalam sebuah pembelajaran dilakukan melalui jaringan (network). Ini berarti dengan elearning memungkinkan tersampaikannya bahan ajar kepada siswa menggunakan media teknologi informasi dan komunikasi berupa komputer dan jaringan internet atau intranet. Dengan e-learning belajar bisa dilakukan kapan saja, di mana saja, dan dengan kecepatan akses apapun. Proses pembelajaran berlangsung efisien dan efektif.

MOODLE merupakan salah satu aplikasi $e$ learning yang berbasis open source. Istilah moodle diambil dari singkatan Modular Object Oriented Dynamic Learning Enviroment, yang berarti tempat belajar dinamis dengan menggunakan model berorientasi objek. Moodle memberikan paket software lengkap (Moodle+Apache+MySQL+PHP) (Murnir, 2009:180).

Pemanfaatan e-learning pada sebuah pendidikan kejuruan seperti Sekolah Menengah Kejuruan sangat dibutuhkan untuk membantu guru dalam meningkatkan proses pembelajaran. Seperti diketahui kemampuan setiap peserta didik di SMK Karya Guna berbeda-beda dalam pemahaman materi di kelas. Ada peserta didik yang cepat menangkap materi yang diberikan guru ketika di kelas dan ada pula peserta didik yang lambat dalam menangkap materi yang diberikan di kelas. Sedangkan waktu yang diberikan peserta didik untuk belajar di kelas adalah 45 menit/jam pelajaran. Dalam waktu tersebut peserta didik dituntut untuk memahami setiap pelajaran yang diberikan oleh guru. Tetapi tidak semua peserta didik mengerti materi pelajaran yang disampaikan guru dan juga keterbatasan waktu untuk peserta didik bertanya mengenai apa yang belum ia pahami dari materi pelajaran yang disampaikan guru. Selain itu, ketika peserta didik sakit, ia tidak dapat hadir di kelas untuk belajar. Akan tetapi peserta didik tetap memiliki hak untuk belajar. Keterbatasan waktu dan tempat dapat mempengaruhi kinerja pengajar dan proses pembelajaran peserta didik dalam kondisi tersebut.

Kemudian materi yang disampaikan guru disetiap pertemuan pasti berbeda. Materi yang diberikan di kelas pun sangat terbatas belum tentu 
guru bisa memberikan materi tambahan kepada peserta didik melihat setiap pertemuan memiliki materi berbeda. Kalaupun guru memberikan ulasan pada awal pembelajaran disetiap pertemuan, pastinya hanya sebagian materi yang akan diulas. Dengan menggunakan e-learning guru dapat memberikan materi tambahan kepada peserta didik kapanpun serta peserta didik dapat mengulas kembali setiap materi yang telah diberikan guru. Peserta didik juga dapat semakin memantapkan tingkat penguasaan terhadap materi pelajaran di dalam kelas menggunakan e-learning dengan mempelajari materi yang diberikan secara berulangulang dimanapun dan kapanpun. Apabila peserta didik mengalami kesulitan memahami materi pelajaran di kelas, maka diberikan kesempatan untuk memanfaatkan materi pembelajaran e-learning yang dirancang untuk mereka.

Melalui kuisioner awal yang diberikan kepada peserta didik XI TKJ 2 SMK Karya Guna 60\% peserta didik memiliki laptop pribadi. Dan penggunaan laptop sendiri masih kurang maksimal dilakukan oleh peserta didik untuk belajar pribadi. Sedangkan peserta didik yang tidak punya laptop $62 \%$ lebih sering ke warnet (warung internet) untuk mengakses internet. Ketika di warnet (warung internet) pun peserta didik masih kurang maksimal dalam menggunakan internet untuk belajar. Dengan e-learning peserta didik dapat memaksimalkan waktunya dalam penggunaan internet melalui laptop ataupun warnet (warung internet) untuk belajar. Peserta didik juga dapat mengakses setiap materi di e-learning kapanpun dan di manapun baik di rumah ataupun di warnet (warung internet).

Agar $e$-learning dapat mendukung proses pembelajaran di SMK Karya Guna, dibutuhkan kesiapan penerimaan sistem $e$-learning di sekolah tersebut. Untuk itu perlu adanya kesiapan penerimaan sistem e-learning pada mata pelajaran Praktik Jaringan Komputer.

\section{DASAR TEORI}

Pada bagian ini diuraikan landasan teoritis yang berhubungan dengan penelitian yang dilakukan.

\subsection{Manfaat e-learning}

Pembelajaran dengan e-learning memiliki banyak manfaat diantaranya: meningkatkan interaksi pembelajaran antara peserta didik dengan pengajar, memungkinkan terjadinya interaksi pembelajaran darimana dan kapan saja (time and place flexibility), menjangkau peserta didik dalam cakupan yang luas (potential to reach aglobal audience), mempermudah penyempurnaan dan penyimpanan materi pembelajaran (easy updating of course as well as archivable capabilities).

\subsection{Kelebihan e-learning}

Menurut Dewi Salma \& Eveline e-learning memiliki kelebihan yaitu tersedianya fasilitas dimana pengajar dan siswa dapat berkomunikasi secara mudah melalui fasilitas internet atau kapan saja kegiatan berkomunikasi dilakukan tanpa dibatasi oleh jarak, tempat dan waktu, siswa dapat belajar (me-review) bahan ajar setiap saat dan dimana saja, berubahnya peran siswa dari yang pasif menjadi aktif, dan relatif lebih efisien

\subsection{MOODLE}

Moodle adalah sebuah nama untuk sebuah program aplikasi yang dapat mengubah sebuah media pembelajaran kedalam bentuk web. Moodle diberikan secara gratis sebagai perangkat lunak open source di bawah lisensi GNU Public License yang artinya meski memiliki hak cipta, MOODLE tetap memberikan kebebasan bagi pengguna untuk menduplikat, menggunakan dan memodifikasinya.

\subsection{Kelebihan dari Moodle}

Beberapa kelebihan dari MOODLE (Melfachrozi, 2006:14) yaitu 100\% cocok untuk kelas online dan sama baiknya dengan belajar tambahan yang langsung berhadapan dengan dosen/guru; sederhana, ringan, efisien dan menggunakan teknologi sederhana; mudah diinstall pada banyak program yang bisa mendukung PHP; menampilkan penjelasan dari pelajaran yang ada dan pelajaran tersebut dapat dibagi kedalam beberapa kategori serta dapat mendukung 1000 lebih pelajaran.

\subsection{TAM (Technology Acceptance Model)}

Melalui TAM, pengguna akan menggunakan system informasi yang baru maka ada dua faktor yang mempengaruhinya yaitu persepsi kemudahan penggunaan (Ease of Use Perceived) maksudnya pengguna meyakini kalau sebuah sistem mudah dalam penggunaannya sehingga tidak memerlukan usaha keras dan akan terbebas dari kesulitan. Dan persepsi kebermanfaatan (Usefulness Perceived) maksudnya pengguna percaya bahwa dengan menggunakan sistem informasi tersebut akan meningkatkan kinerjanya.

\section{METODELOGI PENELITIAN}

Metodelogi yang digunakan pada penelitian ini adalah Research and Development. Adapun langkah-langkah metodelogi penelitian Reseacrh and Development adalah sebagai berikut:

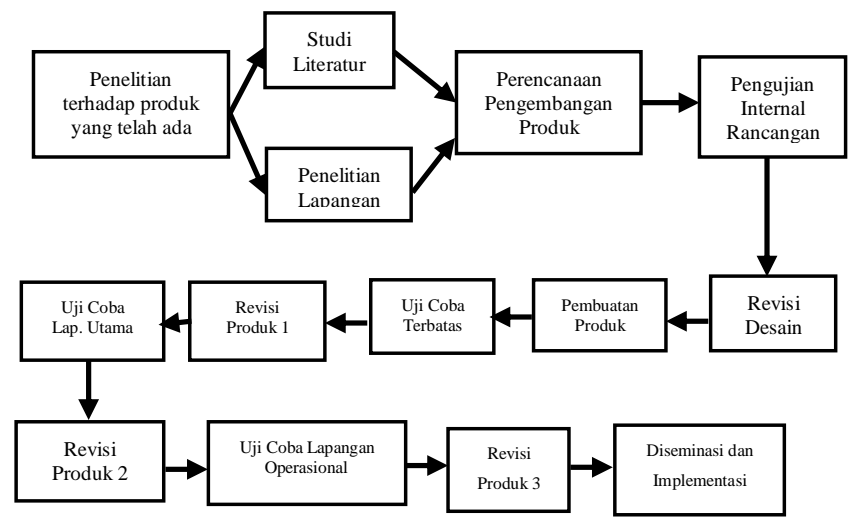


Gambar 3.01 Langkah-langkah Penelitian dan Pengembangan Level 3

\subsection{Tahap Penelitian dan Pengumpulan Informasi}

Pengumpulan informasi dilakukan dengan cara meminta RPP yang dibuat oleh guru mata pelajaran praktik jaringan komputer SMK Karya Guna. Kemudian dilakukan pembuatan materi dari RPP yang diberikan.

\subsection{Tahap Perencanaan Produk}

Tahap penelitian dan pengembangan media pembelajaran berbasis web untuk mata kuliah jaringan komputer pada pokok bahasan routing:

1. Menginstall moodle versi 3.5 dalam bentuk online

2. Menyiapkan fitur-fitur moodle yang akan dibuat meliputi user (administrator, guru, siswa), materi pelajaran (unggah dan unduh) dan kuis/ujian

3. Meminta RPP yang telah dibuat guru mata pelajaran praktik jaringan komputer SMK Karya Guna

4. Menyusun materi melakukan perbaikan dan/atau setting ulang koneksi jaringan berbasis luas (WAN)

5. Mengisi konten moodle. Konten yang ada didalam moodle adalah RPP, materi persentasi, materi pendukung pembelajaran, tugas, dan soal pilihan ganda

6. Menguji produk pada ahli e-learning dan ahli media

7. Menganalisis data hasil uji coba ahli e-learning dan ahli media

8. Menguji produk pada uji coba terbatas

9. Menganalisis data hasil uji coba terbatas

10. Merevisi produk tahap I

11. Menguji produk pada ahli e-learning dan ahli media

12. Menganalisis data hasil uji coba ahli e-learning dan ahli media

13. Menguji produk pada uji coba lapangan utama

14. Menganalisis data hasil uji coba lapangan utama

15. Merevisi produk tahap II

16. Menguji produk pada ahli e-learning dan ahli media

17. Menganalisis data hasil uji coba ahli e-learning dan ahli media

18. Menguji produk pada uji coba lapangan operasional

19. Menganalisis data hasil uji coba lapangan operasional

20. Merevisi produk menjadi produk akhir

\subsection{Tahap Desain Produk}

Tahap perencanaan pembuatan e-learning berbasis moodle untuk mata pelajaran praktik jaringan computer pada pokok bahasan melakukan perbaikan dan / atau setting ulang koneksi jairngan berbasis luas (WAN):
1. Menginstall moodle versi 3.5 dalam bentuk online

2. Menyiapkan fitur-fitur moodle yang akan dibuat meliputi user (administrator, guru, siswa), materi pelajaran (unggah dan unduh) dan kuis/ujian

3. Menyusun materi melakukan perbaikan dan/atau setting ulang koneksi jaringan berbasis luas (WAN)

4. Mengisi konten web pembelajaran
a. RPP
b. Materi presentasi
c. Materi pendukung pembelajaran
d. Tugas
e. Soal pilihan ganda

3.3.1. Menginstall moodle versi 3.5 dalam bentuk online

Menginstall moodle versi 3.5 secara online.

3.3.2. Menyiapkan fitur-fitur moodle yang akan dibuat meliputi user (administrator, guru, siswa), chatting dan kuis/ujian

Memasukkan fitur-fitur user (administrator, guru, siswa), chatting dan kuis/ujian pada moodle yang telah diinstall.

3.3.3. Menyusun materi melakukan perbaikan dan / atau setting ulang koneksi jaringan berbasis luas (WAN)

Penyusunan materi untuk mata pelajaran praktik jaringan komputer pokok bahasan melakukan perbaikan dan / atau setting ulang koneksi jaringan berbasis luas (WAN) dilakukan dengan meminta RPP kepada guru SMK Karya Guna.

\subsubsection{Mengisi konten moodle}

Konten dari moodle berisi RPP, materi persentasi, materi pendukung pembelajaran, tugas dan soal pilihan ganda.

1. RPP RPP yang terdapat didalam moodle penulis dapat dari guru mata pelajaran praktik jaringan komputer.

2. Materi presentasi Materi presentasi dibuat berdasarkan RPP yang diberikan guru SMK Karya Guna tentang materi apa saja yang dibutuhkan untuk mata pelajaran praktik jaringan komputer pokok bahasan melakukan perbaikan dan / atau setting ulang koneksi jaringan berbasis luas (WAN).

3. Materi pendukung pembelajaran Materi pendukung pembelajaran merupakan materi-materi yang mendukung segala bentuk praktik.

4. Tugas

Tugas dibuat sesuai dari beberapa materi yang telah ada

5. Soal pilihan ganda Soal-soal pilihan ganda dibuat dari materi yang telah disiapkan 


\section{Hasil Analisis}

Hasil dari penelitian ini berupa e-learning berbasis moodle untuk mata pelajaran praktik jaringan komputer di SMK Karya Guna.

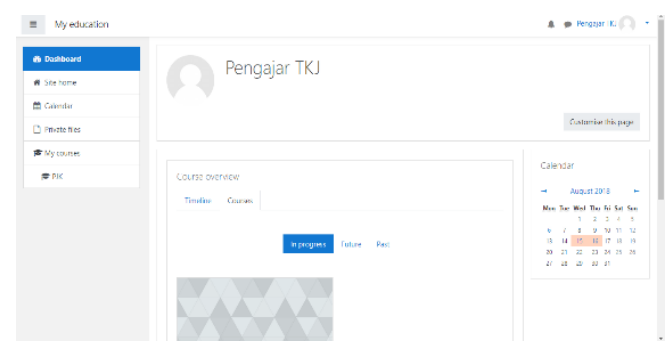

Gambar 4.01 Tampilan Awal Setelah Login Versi 1

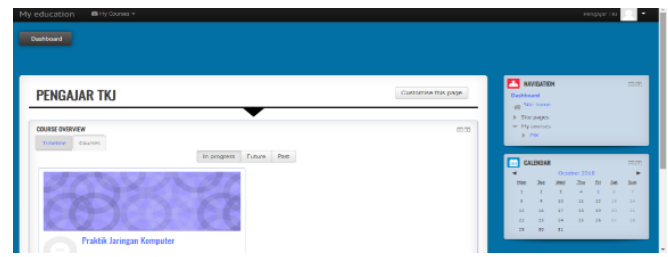

Gambar 4.02 Tampilan Awal Setelah Login Versi 2

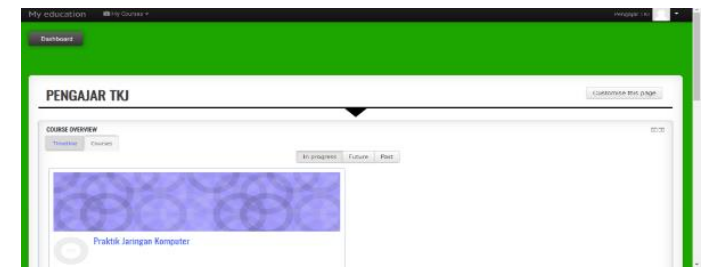

Gambar 4.03 Tampilan Awal Setelah Login Versi 3

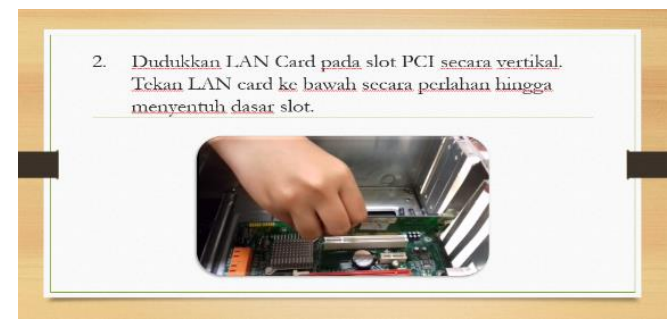

Gambar 4.04 Materi Pendukung Versi 1

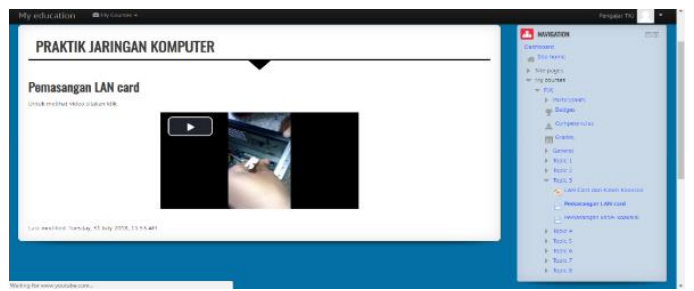

Gambar 4.05 Materi Pendukung Versi 2

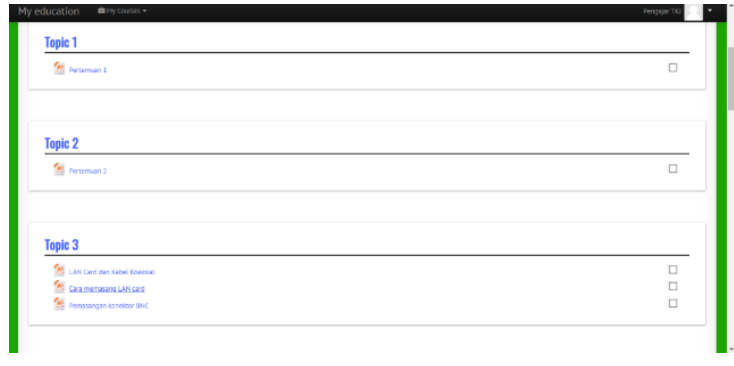

1. Sesuaikan jenis LAN Card dengan slot pada motherboard. Dalam hal ini slot jenis PCI.

Untuk melihat video klik

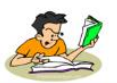

Gambar 4.06 Materi Pendukung Versi 3

\subsection{Tugas}

4.1.1. Tugas Versi 1

Tugas disajikan dalam bentuk online text dimana user (siswa) menjawab pertanyaan secara online dalam bentuk text..

\subsubsection{Tugas Versi 2}

Tugas disajikan dalam bentuk file submission dimana user (siswa) menjawab pertanyaan dengan mengupload jawaban dalam bentuk $m s$. Word dengan maksimal upload hanya 1 kali

4.1.3. Tugas Verso 3

Tugas disajikan dalam bentuk online text dan file submission dimana user (siswa) dapat menjawab pertanyaan secara online dalam bentuk text atau mengupload jawaban dalam bentuk $m s$. Word

\subsection{Ujian}

\subsubsection{Ujian Versi 1}

Ujian (UTS/UAS) disajikan dalam bentuk multiple choice dengan tidak adanya batasan waktu penutupan untuk mengerjakan ujian tersebut. User (siswa) diberikan kebebasan untuk mengerjakan ujian lebih dari satu kali (unlimited).

\subsubsection{Ujian Versi 2}

Ujian (UTS/UAS) disajikan dalam bentuk essay. Ujian ini memiliki batas penutupan selama 1 minggu. Ujian diberikan batasan dalam mengerjakan soal yang yang ada yaitu maskimal sebanyak 2 kali. Ketika siswa mengerjakan ujian ini sebanyak 2 kali, maka penilaian dipilih dari nilai terakhir yang telah diperoleh oleh user (siswa).

\subsubsection{Ujian Versi 3}

Ujian (UTS/UAS) disajikan dalam 2 bentuk yaitu multiple choice dan essay. Ujian ini 
diberikan waktu selama 1 hari dalam pengerjaannya. Ujian diberikan batasan dalam mengerjakaannya yaitu sebanyak 1 kali. Untuk dapat mengakses ujian hanya user (siswa) yang sudah masuk di grup XI TKJ 2 saja.

Tabel 4.11 Hasil Uji Coba Kelompok Besar (Guru)

\begin{tabular}{|l|l|c|c|c|}
\hline No & \multicolumn{1}{|c|}{ Aspek } & $\begin{array}{c}\text { Skor } \\
\text { didapat }\end{array}$ & $\begin{array}{c}\text { Skor } \\
\text { maksimum }\end{array}$ & Efektifitas \\
\hline 1. & $\begin{array}{l}\text { Fitur-fitur yang } \\
\text { memudahkan guru dan } \\
\text { siswa dalam proses } \\
\text { pembelajaran }\end{array}$ & 70 & 75 & $93,33 \%$ \\
\hline 2. & $\begin{array}{l}\text { Moodle mudah } \\
\text { dipelajari }\end{array}$ & 14 & 15 & $93,33 \%$ \\
\hline 3. & $\begin{array}{l}\text { Moodle fleksibel bagi } \\
\text { guru dalam } \\
\text { pembelajaran }\end{array}$ & 27 & 30 & $90 \%$ \\
\hline 4. & $\begin{array}{l}\text { Moodle bermanfaat } \\
\text { bagi guru dalam } \\
\text { meningkatkan } \\
\text { pekerjaannya (proses } \\
\text { pembelajaran) }\end{array}$ & 80 & 90 & $88,89 \%$ \\
\hline 5. & $\begin{array}{l}\text { Moodle efektif dalam } \\
\text { proses pembelajaran }\end{array}$ & 79 & 90 & $87,78 \%$ \\
\hline Total & 270 & 300 & $90 \%$ \\
\hline
\end{tabular}

Tabel 4.12 Hasil Uji Coba Kelompok Besar (Siswa)

\begin{tabular}{|l|l|c|c|c|}
\hline No & \multicolumn{1}{|c|}{ Aspek } & $\begin{array}{c}\text { Skor } \\
\text { didapat }\end{array}$ & $\begin{array}{c}\text { Skor } \\
\text { maksimum }\end{array}$ & Efektifitas \\
\hline 1. & $\begin{array}{l}\text { Materi mudah } \\
\text { dipelajari dan materi } \\
\text { pendukung sudah } \\
\text { tepat }\end{array}$ & 235 & 240 & $97,92 \%$ \\
\hline 2. & $\begin{array}{l}\text { Dapat mengakses } \\
\text { tugas dan ujian } \\
\text { dengan mudah }\end{array}$ & 210 & 240 & $87,5 \%$ \\
\hline 3. & $\begin{array}{l}\text { Kemudahan dalam } \\
\text { berkomunikasi antar } \\
\text { siswa maupun siswa } \\
\text { dengan guru }\end{array}$ & 110 & 120 & $91,67 \%$ \\
\hline 4. & $\begin{array}{l}\text { Mudah dalam } \\
\text { pengoperasiannya }\end{array}$ & 350 & 360 & $97,22 \%$ \\
\hline 5. & $\begin{array}{l}\text { Fleksibel dalam } \\
\text { waktu }\end{array}$ & 220 & 240 & $91,67 \%$ \\
\hline 6. & $\begin{array}{l}\text { Bermanfaat dalam } \\
\text { meningkatkan } \\
\text { kinerja siswa }\end{array}$ & 310 & 360 & $86,11 \%$ \\
\hline 7. & $\begin{array}{l}\text { Relevan dengan } \\
\text { mata pelajaran } \\
\text { praktik jaringan } \\
\text { komputer }\end{array}$ & 115 & 120 & $95,83 \%$ \\
\hline Total & & 1680 & $96 \%$ \\
\hline
\end{tabular}

\section{KESIMPULAN DAN SARAN}

\subsection{KESIMPULAN}

Penelitian ini menghasilkan e-learning berbasis moodle untuk mata pelajaran praktik jaringan komputer pokok bahasan perbaikan dan / atau setting ulang koneksi jaringan berbasis luas (WAN) kelas XI TKJ II SMK Karya Guna Manggarai.

Berdasarkan hasil uji coba yang telah dilakukan, dapat disimpulkan bahwa e-learning berbasis moodle versi ketiga sesuai dan dapat diterima dengan baik untuk diterapkan pada mata pelajaran Praktik Jaringan Komputer pokok bahasan perbaikan dan / atau setting ulang koneksi jaringan berbasis luas (WAN) kelas XI TKJ II SMK Karya Guna.

\subsection{SARAN}

Berdasarkan hasil penelitian dan pengembangan E-learning Berbasis Moodle untuk Mata Pelajaran Praktik Jaringan Komputer pada Pokok Bahasan perbaikan dan / atau setting ulang koneksi jaringan berbasis luas (WAN) di kelas XI TKJ II SMK Karya Guna, penulis menyarankan:

1. Sebagai e-learning berbasis moodle, agar tujuan dapat tercapai secara efektif, guru dapat membiasakan siswa untuk mengakses moodle supaya membantu pemahaman siswa dalam proses pembelajaran.

2. Guru dapat membudayakan penggunaan $e$ learning berbasis moodle guna meningkatkan kemampuan IT kepada siswa.

3. Beberapa fitur dapat ditambahkan dengan mengupgrade versi moodle terbaru agar lebih interaktif.

\section{Daftar Pustaka:}

Deni, D. (2011). Teknologi Pembelajaran.

Bandung: PT Remaja Rosdakarya.

Empy, E. \& Hartono, Z. (2005). E-learning konsep dan aplikasi. Yogyakarta: Andi.

Fatmawati, E. (2015). Technology Acceptance Model (TAM) Untuk Menganalisis Penerimaan Terhadap Sistem Informasi Perpustakaan. Jurnal Iqra, 9(1), 6-7. [Internet]

http://download.portalgaruda.org/article.php?article $=312215 \& \mathrm{val}=7280 \&$ title $=$ TECHNOLOGY $\% 20 \mathrm{~A}$ CCEPTANCE\%20MODEL\%20(TAM)\%20UNTU K\%20MENGANALISIS\%20PENERIMAAN\%20T ERHADAP\%20SISTEM\%20INFORMASI\%20PE RPUSTAKAAN. [4 Oktober 2016].

Ferdinand, X. F. (2009). Integrasi Learning Management System ILIAS Dengan Esai Online Simple-O. [Internet]

lib.ui.ac.id/file?file=digital/20248850-R030932.pdf. Diakses 12 Januari 2017.

Kadek, S. \& Dewa, K. T. (2014). E-learning Berbasis Moodle. Yogyakarta: Graha Ilmu.

Munawar Akhmad. (2009). Pengembangan Elearning Berbasis Moodle Sebagai Penunjang Perkuliahan Di Jurusan Teknik Elektro Universitas Negeri Semarang.[Internet] http://www.lib.unnes.ac.id/901/1/2310.pdf. [16 September 2016].

Nova S. A. (2015). Perancangan Implementasi E-learning Berbasis Moodle Dalam Mata Kuliah Statistika Program Studi Pendidikan Teknik Informatika Dan Komputer [skripsi]. Jakarta: Fakultas Teknik, Universitas Negeri Jakarta.

Numiek, S. H. (2013). Keefektifan e-learning sebagai media pembelajaran (studi evaluasi model pembelajaran e-learning SMK Telkom Sandhy 
Putra Purwokerto). Jurnal Pendidikan Vokasi, 3 (1), 90-102. [Internet]

www.journal.uny.ac.id/index.php/jpv/article/viewFi le/1584/1314. [11 Mei 2016]

Sugiyono. (2015). Metode Penelitian dan

Pengembangan (Research and Development/R\&D).

Bandung: Alfabeta.

Zaeri, K. (2015). Pengembangan Aplikasi E-

learning Berbasis Moodle Untuk Pembelajaran

Mata Kuliah Logika Fuzzy Di Program Studi

Pendidikan Teknik Elektro [skripsi]. Jakarta:

Fakultas Teknik, Universitas Negeri Jakarta. 